\title{
The relationship between personality and performance of football referees
}

Pirooz Sayfollahpour

Student, Physical Education Department, Islamic Azad University, South Branch, Tehran, Iran

\section{Farideh Ashraf Ganjooee}

Member, Physical Education Department, Islamic Azad University, Central Branch, Tehran, Iran

\section{Reza Nikbakhsh}

Member, Physical Education Department, Islamic Azad University, South Branch, Tehran, Iran

DOI: $\quad$ 10.6007/IJARBSS/v3-i9/184 URL: http://dx.doi.org/10.6007/IJARBSS/v3-i9/184

\begin{abstract}
After coaches and athletes, referees are the third side of sporting events. If the judgment is done properly, the result of competition will be determined according to skill and tactical superiority; otherwise, other environmental factors may affect the result of competition. Personality is one of the distinctive aspects of every individual's life. Personality characteristics predispose an individual to perform various actions in specific situations. Football is one of the most stressful jobs and it seems personality is one the most important factors in Judgment method of referees. This study examines the relationship between extraversion, agreeableness, conscientiousness, neuroticism, openness to experience and performance of referees. The research method used was correlation. All 61 premier League Soccer's Referees (the season 2012-2011) were selected as the study population. Due to the limitation of population, all subjects were considered as the sample. The NEO Personality Inventory (60 items and 5 scales) was used. For collecting the data, researcher visited Tehran's referees in their training location; questionnaire was sent via e-mail to the referees in other cities. The SPSS software was used for data analysis. Results showed that there was significant relationship between personality dimensions and judgment methods. There was a positive relationship between flexibility and judgment quality. Also, the present study showed there was not significant relationship between neuroticism, extraversion, agreeableness and judgment quality.

Keywords: personality characteristics, judgment, football, performance, judgment quality.
\end{abstract}

\section{Introduction}

After coaches and athletes, referees are the third side of sporting events and are responsible for the most difficult tasks in sports. If the judgment is done properly, the result of competition will be determined according to skill and tactical superiority; otherwise, other environmental factors may affect the result of competition and the athletes and spectators will not enjoy a challenging competition. Personality is one of the distinctive aspects of every individual's life. Thus we can say personality is the set of characteristics. Sport effectively changes social aspects 
of a person's personality or their social competence. Sport is generally full of opportunities for dealing with obstacles and problems and adopting best methods for removing them. This situation is important in terms of mental health. In fact, selecting the methods of exercise that can overcome barriers is important in terms of mental health. It not only makes a person feel satisfied, but also causes resistant, curious, intelligent, flexible and tolerant spirit in dealing with obstacles and difficulties. Therefore, overcoming the tensions and problems in sport may increase the athlete's sense about their competence and self-control, increase their intrinsic motivation for appropriate behavior, and influence positively their personality. Personality characteristics predispose individuals to perform various actions in specific situations (Austin et al, 2004). It seems personality is one the most important factors in Judgment method of referees regarding football.

Regardless of management structure, football is consisted of elements such as athletes, coaches, spectators and referees. Currently judgment like other sections is getting to be scientific; it requires education and experience. The referee in the football field is not only responsible for directing referees team, but also his/her decisions may affect behaviors and actions of all players, coaches, fans and practitioners of competitions and clubs (Hampton 2006).

Referees are one of the core members of sports competitions. Due to their persistence, efforts and expertise, all fields of sports have continued around the world. After coaches and athletes, referees are the third side of sporting events responsible for the most difficult tasks in sports. Judgment in sport is one of several businesses requires the ability to make decisions in a short period of time. Decision making should be fast and steady. Thus, attention and concentration are critical factors that referees should have a maximum level of them; therefore, they could take rapid and successive decisions when they are under psychological pressures .

Many psychologists believe that personality is consisted of five characteristics: extraversion, agreeableness, conscientiousness, neuroticism, and openness to experience.

\section{Research objectives}

The relationship between personality characteristics and performance of referees in Iran's Premier Football League

1) The relationship between extraversion and referees' performance

2) The relationship between agreeableness and referees' performance

3) The relationship between conscientiousness and referees' performance

4) The relationship between neuroticism and the referees' performance

5) The relationship between openness to experience and referees' performance

1) There is relationship between extraversion and referees' performance.

2) There is relationship between agreeableness and referees' performance.

3) There is relationship between conscientiousness and referees' performance.

4) There is relationship between neuroticism and the referees' performance.

5) There is relationship between openness to experience and referees' performance.

\section{Background}

In a research on the impact of personality on job performance, Allameh et al (2011) concluded there is a significant and positive relationship between conscientiousness and performance. 
In a research on personality as a predictor of athletic performance, Manooj and Singh (2012) found that only neuroticism has a positive relationship with athletic performance.

In a research on the relationship between personality and performance motivation, Jaj and Ellis (2002) found that neuroticism and conscientiousness are the most important predictors of performance motivation.

In a research on personality characteristics and athletic performance, Pidment et al (1999) found that only conscientiousness has a positive relationship with athletic performance.

In a study on five factors personality dimensions and job performance, Barik (1991) concluded only conscientiousness has a significant relationship with job performance.

\section{Methodology}

The research method used was correlation. In this study, personality characteristics and referees performance were considered as predictor variable and criterion variable, respectively. All 61 Premier League Soccer's Referees (the season 2012-2011) were selected as the study population. Due to the limitation of population, all subjects were considered as the sample.

NEO personality Inventory was made based on Costa and McCrae's five factor theory of personality. The questionnaire was revised in 1992 and reduced to 60 items; it includes five scales: extraversion, agreeableness, conscientiousness, neuroticism, and openness to experience. Subjects responded in the four-choice items (from strongly agree to strongly disagree). The Cronbach's alpha coefficient for extraversion, agreeableness, conscientiousness, neuroticism, and openness to experience obtained $0.85,0.84,0.92,0.88$, and 0.78 , respectively. The reliability coefficients were reported 0.85 .

For collecting the data, researcher visited Tehran's referees in their training location; questionnaire was sent via e-mail to the referees in other cities. The purpose of the study was explained to the referees; they were asked to complete the questionnaire carefully. Each subject filled the questionnaire in about 45 minutes. Judgment scores of Premier League referees during the 2011-2010 season was received from referees committee.

Statistical methods used in this study were both descriptive and inferential statistics. Mean, frequency, standard deviation, percentage, and correlation coefficient was used for analyzing the data.The SPSS software was used for data analysis.

One sample T-test was used for evaluating research variables. Pearson correlation test was used for examining research hypotheses. 


\section{Findings}

Table 1:Pearson correlation coefficients between dimensions of personality and emotional exhaustion

\begin{tabular}{llllllll}
\hline selbairav & $\mathbf{1}$ & $\mathbf{2}$ & $\mathbf{3}$ & $\mathbf{4}$ & $\mathbf{5}$ & $\mathbf{6}$ \\
\hline & $\begin{array}{l}\text { Pearson } \\
\text { correlation } \\
\text { coefficient }\end{array}$ & 1 & & & & & \\
& & & & & &
\end{tabular}

1. neuroticism

Significance

coefficients

) SIG (

$\begin{array}{lll}\text { Pearson } & & \\ \text { correlation } & 0.44^{* *} & 1 \\ \text { coefficient } & & \end{array}$

2. extraversion

Significance

coefficients

0.00

) SIG (

Pearson

correlation

$\begin{array}{lll}0.01 & -0.04 & 1\end{array}$

coefficient

3. ytilibixelf

$\begin{array}{lll}\text { Significance } & & \\ \text { coefficients } & 0.93 & 0.77 \\ \text { ) SIG ( } & & \end{array}$

Pearson

correlation

$-0.14 \quad 0.05$

$0.33^{* *} \quad 1$

coefficient

4. agreeableness

Significance

coefficients

$\begin{array}{lll}0.27 & 0.72 \quad 0.01\end{array}$

) SIG (

Pearson

correlation

$\begin{array}{lllll}-0.06 & 0.12 & 0.78^{* *} & 0.19 & 1\end{array}$

coefficient

5. conscientiousness

Significance

coefficients

) SIG ( 


\begin{tabular}{|c|c|c|c|c|c|c|c|}
\hline \multirow[b]{2}{*}{ 6. Judgment scores } & $\begin{array}{l}\text { Pearson } \\
\text { correlation } \\
\text { coefficient }\end{array}$ & -0.07 & -0.01 & $0.62^{* *}$ & -0.01 & $0.75^{* *}$ & 1 \\
\hline & $\begin{array}{l}\text { Significance } \\
\text { coefficients } \\
\text { ) SIG ( }\end{array}$ & 0.58 & 0.92 & 0.00 & 0.95 & 0.00 & \\
\hline
\end{tabular}

**. $\mathrm{P}<0.01 * . \mathrm{P}<0.05$

Pearson's test results indicate that there is a significant relationship between personality dimensions and judgment scores. There is a significant and positive relationship between judgment scores, flexibility $(p=0.00, r=0.62)$, and conscientiousness $(p=0.00, r=0.75)$. There is no significant relationship among neuroticism $(p=0.58, r=0.07)$, extraversion $(p=0.92, r=0.01)$, agreeableness $(p=0.95, r=0.01)$, and judgment scores.

Table 2:Cronbach's alpha coefficients for personality dimensions

\begin{tabular}{llll}
\hline & Cronbach's alpha & $\begin{array}{l}\text { deleted } \\
\text { question }\end{array}$ & $\begin{array}{l}\text { Cronbach's alpha after deleted } \\
\text { question }\end{array}$ \\
\hline neuroticism & 0.71 & - & - \\
extraversion & 0.70 & - & - \\
ytilibixelf & 0.74 & - & - \\
agreeableness & 0.72 & - & - \\
& & - & - \\
conscientiousness & 0.84 & - & - \\
\multicolumn{1}{c}{ general } & 0.82 & & \\
$\begin{array}{l}\text { The } \\
\text { personality } \\
\text { dimensions }\end{array}$ & & - & \\
\hline
\end{tabular}

In this study, the research hypotheses and objectives were analyzed through correlation and regression methods. The results showed that there is a significant relationship between personality dimensions and judgment scores. Also, the results showed that there is a significant and positive relationship between flexibility, conscientiousness, and the judgment quality of referees; but there is no significant relationship between neuroticism, extraversion, and agreeableness. Also, regression results indicate that personality dimensions cannot predict judgment quality of Premier League referees. 
Discussion and conclusions

This study investigated the relationship between personality characteristics and judgment quality of Iran Premier League's football referees. The results showed that there is a significant relationship between personality characteristics and judgment quality of referees; the reason could be the differences in the sport environment and other activity environments and factors affecting them. In terms of conscientiousness dimension, the findings of this study are consistent with Allameh et al (2011Pidment et al (1999), and Barik (1991) results; possible reason for this can be the similarity of used tools. The other result was positive relationship between flexibility and judgment quality. This result suggests that the referees have the agreeableness ability to deal with pressures and tensions during the game. In terms of flexibility dimension, the results were inconsistent with Singh and Manvj (2012), and idmen and Scofield (2004) findings; possible reasons for this discrepancy can be difference in age, population, and used instruments.

The results showed that there is no significant relationship between neuroticism, extraversion, agreeableness, and judgment quality. The results of this research were inconsistent with Allameh et al (2011), findings; a possible reason could be the difference in population, gender and used tools. The limitations of this study include education of the respondents, the cultural status of respondents, respondents' honesty, and availability of the respondents.

\section{Acknowledgements}

We would like to thank Mr.Heidary for the technical and publication cooperation.

\section{References}

Allameh, M., Ghafari, M. J Basic Appl Sci Res, (2012), 2(6)6293-6299.

Austin , E. J. ( 2004 ). An investigation of the relationship between trait emotional intelligence and emotional task performance . Personality and Individual Differences , 36 , 1855 - 1864 .

Barrick, M.R. \& Mount, M.K. (1991). The big five personality dimensions and job performance: A meta-analysis. Personnel Psychology, 44, 1-26.

- Costa, P.T., JR. \& McCrae,R.R.. (1992). The Neo Personality Inventory Manuel. Odessa, FL: Psychological Assessment Resource.

Hampton, M. (2006). The bigger picture, Capital referee London, FA.

Piedmont, R., Hill, D., Blanco, S. Personality and Individual Differences, (1999), 27, 4; 769-777. Singh, G., Manoj, K. VSRD Tech \& Non-Tech J, 2012, Vol. 3 (8). 